\title{
Os riscos ambientais no Brasil devido ao uso do defensivo Malathion Emulsão Aquosa - EA 44\% no controle de Aedes Aegypti (Linnaeus, 1762) (díptera; culicidae): uma revisão
}

O mosquito Aedes aegypti (conhecido como mosquito da dengue ou pernilongo rajado), vem se espalhando em quase todo o planeta, principalmente nas regiões tropicais e subtropicais. $O$ Aedes aegypti é o principal vetor de múltiplas doenças, como dengue, zika e chikungunya. Uma das estratégias em muitos municípios brasileiros na tentativa de combater esse mosquito é a utilização do 'Fumacê', um defensivo líquido que tem na sua principal composição Malathion em Emulsão Aquosa (EA) $44 \%$. 0 presente estudo teve como objetivos identificar quais os efeitos negativos para seres vivos e meio ambiente devido ao uso inadequado do Malathion no combate ao mosquito da dengue. Foi realizado um levantamento nas bases de dados (PUBMED, Science Direct e Google Scholar), nos últimos cinco anos (2014-2018), usando as restrições ou combinações de termos: 'Malathion', 'Malation', 'Malatião', 'Aedes aegypti', 'A. aegypti', 'Mosquito da Dengue', 'Inseticida', 'Organofosforado', 'Animais Nocaute', 'Intoxicação'. A pesquisa procurou identificar dados sobre riscos do uso inadequado do Malathion para a saúde humana, a toxicidade do defensivo, o impacto sobre o meio-ambiente, as alternativas de biorremediação e algumas opções biotecnológicas. Desta forma, o defensivo Malathion através de estudos in vivo em animais como: Cyprinus carpio (carpas); Rattus norvegicus (ratos Wistar) e testes in vitro com células de linhagens humanas mostrou efeitos tóxicos em baixas concentrações. Estes dados revelam a necessidade de mais estudos sobre este defensivo para melhor entendimento de seus efeitos sobre os seres vivos e o meio ambiente.

\section{The environmental risks in Brazil due to the use of defensive Malathion Water Emulsion - WE 44\% for the control of Aedes Aegypti (Linnaeus, 1762) (díptera; culicidae): a review}

\begin{abstract}
The mosquito Aedes aegypti (known as dengue mosquito or brindle mosquito) has been spreading almost everywhere on the planet, especially in the tropical and subtropical regions. Aede aegypti is the main vector of multiple diseases, such as dengue, zika infection and chikungunya. One of the strategies in many Brazilian municipalities in the attempt to combat this mosquito is the use of "Fumacê", a liquid pesticide that has in its main composition Malathion Water Emulsion - WE 44\%. The present study aimed to identify the negative effects on living beings and the environment due to the inadequate use of Malathion in the control of the dengue mosquito. A database survey (PUBMED, Science Direct and Google Scholar) was conducted over the last five years (2014-2018) using the constraints or combinations of terms: 'Malathion', 'Malation' 'Malatião' 'Aedes aegrpti', 'A. aegrpti' 'Dengue Mosquito', 'Insecticide',

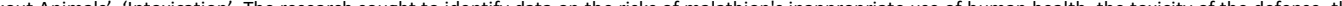
'Organ nd in vitro tests with human lineage cells showed toxic effects at low concentrations. These data reveal the need for further studies on this defensiv to understand better its effects on living things and the environment.
\end{abstract}

Keywords: Dengue Mosquito; Environment; Biotechnology; Waste Management.

Topic: Planejamento, Gestão e Políticas Públicas Ambientais

Reviewed anonymously in the process of blind peer.
Received: 06/10/2020

Approved: 28/11/2020
Clenivaldo Pires da Silva (iD)

Universidade Estadual de Maringá, Brasil http://lattes.cnpq.br/8687308404113173

http://orcid.org/0000-0003-3568-7896

clenivaldo2015@gmail.com

Gustavo Kenji Doi Sakamoto (iD

Universidade Estadual de Maringá, Brasil

http://lattes.cnpq.br/3558784550148445

http://orcid.org/0000-0003-1212-8012

gustavokdsakamoto@gmail.com

Mauricio Pires de Pontes (iD

Universidade Estadual de Maringá, Brasil

http://lattes.cnpq.br/4275081660366743

http://orcid.org/0000-0002-6094-2214

mauricioppontes@hotmail.com

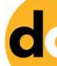

DOI: 10.6008/CBPC2179-6858.2020.006.0051

\author{
Ruan Rompato Vieira (iD \\ Universidade Estadual de Maringá, Brasil \\ http://lattes.cnpq.br/7015330658704984 \\ http://orcid.org/0000-0003-3592-8522 \\ rompatoruan@gmail.com \\ Jean Paulo Silva Natal (iD \\ Universidade Estadual de Maringá, Brasil \\ http://lattes.cnpq.br/6465645151522534 \\ http://orcid.org/0000-0001-6021-6442 \\ jeanpsnatal@gmail.com \\ Helio Conte (iD \\ Universidade Estadual de Maringá, Brasil \\ http://lattes.cnpq.br/7805899028515988 \\ http://orcid.org/0000-0002-2090-0554 \\ helconte@gmail.com
}

Referencing this:

SILVA, C. P.; SAKAMOTO, G. K. D.; PONTES, M. P.; VIEIRA, R. R.; NATAL, J. P. S.; CONTE, H.. Os riscos ambientais no Brasil devido ao uso do defensivo Malathion Emulsão Aquosa - EA 44\% no controle de Aedes Aegypti (Linnaeus, 1762) (díptera; culicidae): uma revisão. Revista Ibero Americana de Ciências Ambientais, v.11, n.6, p.638-646, 2020 DOI: http://doi.org/10.6008/CBPC2179-6858.2020.006.0051 


\section{INTRODUÇÃO}

O mosquito Aedes aegypti (conhecido como mosquito da dengue ou pernilongo rajado), pertence a Ordem Díptera, família Culicidae, originário do Egito, do continente Africano, atualmente vem se espalhando em quase todo o planeta, principalmente nas regiões tropicais e subtropicais. O Brasil encontra-se na faixa intertropical, ou seja, entre os Trópicos de Câncer e Capricórnio. Assim, o mosquito e as arboviroses transmitidas por ele constituem um grande obstáculo para a saúde pública no Brasil e no mundo (SANTOS et al., 2018).

O Aedes aegypti é o principal vetor de múltiplas doenças, como dengue, zika e chikungunya e devido as modificações em padrões climáticos, sua distribuição geográfica está em constante evolução (VALDEZ et al., 2018). Em levantamento realizado pelo Ministério da Saúde (2018) foi revelado que 1.153 municípios brasileiros (que corresponde a $22 \%$ do total de municípios), possuem um alto índice de infestação e risco de surto para dengue, zika e chikungunya.

Em consequência, uma das estratégias de muitos municípios para combater o mosquito vem sendo o uso do Fumacê, um defensivo líquido que tem na sua principal composição Malathion em emulsão aquosa (EA) 44\% (BRASIL, 2014). Sua forma de dispersão é por pulverizador, que gera uma nuvem de partículas finas em pleno ar, o que possibilita amplificar a área de contato com o inseto em pleno voo. Em muitos casos, o pulverizador está equipado em um carro (conhecido como 'Carros do Fumacê'), ou por nebulizadores costais na qual a aplicação espacial é sob Ultra Baixo Volume (UBV). Assim a distribuição é feita em áreas rurais e urbanas.

O Malathion (Melatião ou Malation) é um inseticida de amplo espectro para uso agrícola, industrial e de uso doméstico ao ar livre para o tratamento de ectoparasitas (REED et al., 2014). Pertence ao grupo dos organofosforados e atua na inibição da colinesterase do sistema nervoso do inseto (BRASIL, 2014). A Agência Internacional de Pesquisa em Câncer - IARC (2015), considera o inseticida como um provável carcinógeno, existindo evidências significativas de vários estudos sobre exposições, principalmente em áreas agrícolas nos Estados Unidos, Canadá e Suécia, publicados a partir de 2001. O inseticida ainda pode causar tumores, conforme citado em estudos utilizando roedores (IARC, 2015).

Considerando que já existem inúmeras ações na justiça e relatos na imprensa brasileira de contaminação por este inseticida, o presente estudo teve como objetivos identificar - a partir de levantamento bibliográfico nos últimos cinco anos - quais os efeitos negativos em seres vivos e no meio ambiente devido ao uso inadequado do Malathion no combate ao mosquito da dengue.

\section{METODOLOGIA}

Foi realizado um levantamento nas bases de dados (PUBMED, Science Direct e Google Scholar), no período de 2014 a 2018, usando restrições ou combinações de termos: 'Malathion', 'Malation', 'Malatião', 'Aedes aegypti', 'A. aegypti', 'Mosquito da Dengue', 'Inseticida', 'Organofosforado', 'Animais Nocaute', 'Intoxicação'. Os termos foram agrupados em três grupos: Os Riscos do uso inadequado do Malathion na 
Os riscos ambientais no Brasil devido ao uso do defensivo Malathion Emulsão Aquosa - EA 44\% no controle de Aedes Aegypti (Linnaeus, 1762) (díptera; culicidae): uma revisão

SILVA, C. P.; SAKAMOTO, G. K. D.; PONTES, M. P.; VIEIRA, R. R.; NATAL, J. P. S.; CONTE, H.

Saúde Humana; Os Riscos Ambientais do Uso do Malathion no Meio ambiente; e a Biorremediação e Alternativas Biotecnológicas do Malathion.

\section{Os riscos do uso inadequado do Malathion na saúde humana}

O mosquito da dengue é um dos principais desafios de saúde pública no Brasil e as atividades de prevenção e controle dessa patologia vêm sendo baseadas na estratégia de gestão integrada proposta em políticas de saúde (PESSOA et al., 2016). Segundo Santos et al. (2016), as formas de controle do A. aegypti, são química e mecânica, sendo as mais difundidas por serem utilizadas por agentes de endemias nas residências ou locais públicos.

No controle químico utilizam produtos químicos, que podem ser neurotóxicos, análogos de hormônio juvenil e inibidores de síntese de quitina para matar larvas e insetos adultos (ZARA et al., 2016). Assim, os Agentes Comunitários de Saúde (ACS) e Agentes de Combate a Endemias (ACE), em parceria com a população, são responsáveis por promover o controle mecânico e químico do vetor (ZARA et al., 2016).

Neste sentido, Pessoa et al. (2016), mencionam que os atores centrais são os ACSs (Agentes Comunitários de Saúde) e os ACEs (Agentes de Combate a Endemias), sendo estes que manipulam os agentes químicos e os agrotóxicos, e permanecem mais expostos aos fatores de risco a saúde, pois as aplicações são realizadas com equipamento portátil costal ou acoplado a veículos, com função específica para eliminar formas adultas de $A$. aegypti, devendo serem utilizados somente para bloqueio de transmissão e para controle de surtos ou epidemias (ZARA et al., 2016).

Neste caso, o Malathion é aplicado na forma oleosa no controle do vetor da dengue $A$. aegypti, sob forma de nebulização, o que requer o uso de equipamentos de proteção individual (EPI) pelos aplicadores. Mesmo utilizando EPIs, os agentes aplicadores estão expostos ao inseticida, isto é, as vestimentas não são capazes de reter o produto e este acaba migrando para a pele. Além disso, a lavagem da vestimenta não é capaz de remover completamente o inseticida, representando uma fonte de contaminação (LEME et al., 2014). No entanto, em uma nota Técnica emitida pela $\operatorname{ABRASCO}^{1}$ (2016), as recomendações pelo Ministério da Saúde para o uso de Malathion na Emulsão Aquosa - EA é de 44\%, com adoção de nebulizações sendo o envenenamento potencialmente, mais amplo e perigoso.

\section{A toxicidade do defensivo Malathion}

Na classificação da IARC, o Malathion está contido no grupo 2A, definido como provável carcinogênico em humanos. Com a aplicação do sistema de características-chave (KC), contidos em monografias do IARC, verificou-se que esse inseticida é genotóxico, induz estresse oxidativo, inflamação crônica, modula efeitos receptor-mediador e altera proliferação celular. Para o inseticida em questão, a

\footnotetext{
${ }^{1}$ ABRASCO (Associação Brasileira de Saúde Coletiva), foi criada com o objetivo de atuar como mecanismo de apoio e articulação entre os centros de treinamento, ensino e pesquisa em Saúde Coletiva para fortalecimento mútuo das entidades associadas e para ampliação do diálogo com a comunidade técnico-científica e desta com os serviços de saúde, as organizações governamentais e não governamentais e a sociedade civil. Disponível em: https://www.abrasco.org.br/site/sobreaabrasco
} 
Os riscos ambientais no Brasil devido ao uso do defensivo Malathion Emulsão Aquosa - EA 44\% no controle de Aedes Aegypti (Linnaeus, 1762)

classificação foi baseada em suficiente evidências em animais, limitada evidência em humanos e forte evidência do mecanismo (genotoxicidade e estresse oxidativo) (GUYTON et al., 2018).

Em um estudo utilizando C. carpio (carpas), verificou-se que o Malathion afeta negativamente o perfil hematológico, suprime a resposta imune específica e não-específica, causa estresse oxidativo e o tratamento com própolis previne significativamente os efeitos tóxicos provocados pelo Malathion, além do potencial uso como imunoestimulante (YONAR et al., 2014).

O inseticida Malathion demonstrou ser citotóxico para R. norvegicus (ratos Wistar), com significante redução no número de espermatozoides produzidos pelos túbulos seminíferos, além de afetar a sua qualidade durante a maturação e capacidade de trânsito pelo epidídimo, e aumento no nível de teratozoospermia (ESPINOZA-NAVARRO et al., 2014). Estudos em animais demonstram que a exposição ao inseticida induz diminuição no peso de testículos, epidídimo, vesícula seminal e próstata, diminui densidade do esperma testicular e epididimal, suprime o nível sérico de testosterona e altera a espermatogênese (SEUNGUPTA et al., 2014).

Em estudo in vitro utilizando e comparando a genotoxicidade do Malathion e do isomalation, em células de fígado humano metabolicamente competentes da linhagem HepaRG demonstrou que ambos apresentam efeitos genotóxicos em baixas concentrações sendo que o isomalation apresentou maiores efeitos tóxicos. O isomalation é considerado uma das principais impurezas do Malathion, em grau técnico (JOSSE et al., 2014).

Há relato de caso, da ocorrência de hepatite tóxica e pancreatite aguda por exposição secundária ao Malathion em um indivíduo residente de zona rural no Japão (JAMES et al., 2018).

\section{Impacto sobre o meio-ambiente}

Segundo Coleone (2014), a tecnologia de aplicação de inseticidas a UBV (Ultra Baixo Volume) vem sendo utilizada desde o início da década de 1960 e os primeiros documentos de normatização desta técnica foram realizados pelo Exército Americano. Portanto, a sua aplicação objetiva a eliminação das fêmeas de $A$. aegypti em áreas de riscos de epidemia, e há a necessidade de lavagem dos equipamentos e veículos, sendo um item que merece atenção especial da gestão estadual e municipal, de maneira a evitar a contaminação ambiental com a destinação inadequada dos resíduos e sobras das soluções e da água de lavagem.

Um bom exemplo de mal-uso e de não destinação adequada, mesmo que em concentrações baixas, foi a presença de resíduos de inseticidas, incluindo o Malathion, detectados em um rio localizado no Pantanal, o que comprova o potencial do transporte de inseticidas para ambientes aquáticos (POSSAVATZ et al., 2014). O uso dos pesticidas na agricultura tradicional, vem considerando o Malathion como um possível substituto ao DDT “Dicloro-Difenil-Tricloroetano" (COLEONE, 2014). No Brasil, o Malathion EA 44\% está sendo usado nos seguintes insetos pragas (Tabela 1 ).

O Malathion, muitas vezes é usado como protetor de semente sendo que Gularte et al. (2018), avaliaram o efeito do tratamento de sementes com diferentes doses do inseticida organofosforado na 
Os riscos ambientais no Brasil devido ao uso do defensivo Malathion Emulsão Aquosa - EA 44\% no controle de Aedes Aegypti (Linnaeus, 1762)

qualidade fisiológica e desenvolvimento de plântulas de arroz, para possível utilização como safener. Segundo os mesmos, os resultados demonstraram que as sementes e plântulas, tiveram a carga e expressão genética de diferentes das cultivares.

Tabela 1: Malathion 440 EW. Frasco e bombona (COEX) de 1; 5 e 10 litros. Balde (COEX e Aço) de 20 L. Tambor de aço de 100; 200 e 1000 L. Contêiner de 10000 e 15000 L.

\begin{tabular}{l|l|l}
\hline \multirow{2}{*}{ Cultura } & Praga & Nome(s) Vulgar(es) \\
\cline { 2 - 3 } & Nome Científico & Bicho-furão \\
\hline Citros & Ecdytolopha aurantiana & Cigarrinha-da-cvc \\
Citros & Oncometopia facialis & Mosca-das-frutas; Mosca-do-mediterrâneo \\
Citros & Ceratitis capitata & Pulgão-lanígero; Pulgão-lanígero-da-macieira \\
Maçã & Eriosoma lanigerum & Mosca-das-frutas; Mosca-do-mediterrâneo \\
Pêssego & Ceratitis capitata & Pulgão-da-falsa-crespeira; Pulgão-pardo-do-pessegueiro \\
Pêssego & Anuraphis schwartzi & Pulgão; Pulgão-da-couve \\
Repolho & Brevicoryne brassicae & Curuquerê-da-couve; Lagarta-da-couve \\
Repolho & Ascia monuste orseis & Pulgão-verde; Pulgão-verde-claro \\
Tomate & Myzus persicae & Broca-pequena-do-fruto; Broca-pequena-do-tomateiro \\
Tomate & Neoleucinodes elegantalis
\end{tabular}

Fonte: AGROFIT (2018).

Além disso, a exposição a inseticidas e outros xenobióticos é capaz de alterar o perfil comportamental de espécies aquáticas. Em um estudo, Melo (2018), avaliou a recuperação de peixes juvenis de tilápia Oreochromis niloticus após a exposição aguda a concentrações de Malathion nas águas de diferentes porcentagens de mortalidade. As concentrações de 3,0, 4,5, 5,0 e 7,0 mg.L-1 de Malathion nas águas causaram a mortalidade, respectivamente de $17,5 \%, 27,5 \%, 45,0 \%$ e $55,0 \%$ dos peixes expostos. Também foi observado a ocorrência de sinais clínicos e alterações histológicas em brânquias, rins e fígado nos animais:

O Malathion causa nas tilápias: letargia, secreção de muco, natação errática, mudança na pigmentação da pele, aumento do batimento opercular, espasmos musculares e perda da capacidade de arfagem. Nas brânquias, causa hiperplasia, fusão lamelar, congestão do seio venoso e desarranjo lamelar. No fígado, causa congestão dos sinusóides, deslocamento nuclear, esteatose e desarranjo cordonal. No rim, causa vacuolização das células dos túbulos renais, infiltrado inflamatório e aumento do espaço de Bowman. (MELLO, 2018)

Outro organismo aquático fonte de pesquisa que comprovou ser também afetado pela lixiviação de Malathion foi o caranguejo de água doce da espécie Barytelhusa cunicularis (Westwood, 1836), tendo comprovado que os tecidos histopatológicos do trato reprodutivo sofreram alterações (SINHA et al., 2018).

Estudos demonstram que o Malathion em grau comercial $(50 \% \mathrm{CE})$ tem uma concentração letal média de 7,5 mg/l para os girinos da espécie Duttaphrynus melanostictus e que mesmo em doses menores pode causar grave ameaça para o animal, já que as características morfológicas e comportamentais são afetadas, sendo assim um indicativo de como o Malathion afeta o ecossistema prejudicando a conservação do habitat aquático (DAVID et al., 2015).

Com a finalidade de identificar uma forma de prevenção ou remediação de ambientes atingidos por Malathion estão sendo desenvolvidas, através da biotecnologia, metodologias que experimentalmente se demonstraram eficazes. Um método altamente sensível, seletivo e rápido foi desenvolvido para a detecção colorimétrica do Malathion, e pode auxiliar na deteç̧ão de ambientes contaminados por esse agrotóxico. 0 método emprega nanopartículas de ouro não modificadas, aptâmero específico para malatião e um péptido catiônico. Na presença de Malathion as nanopartículas tornam-se azuis, e em sua ausência apresentam 
Os riscos ambientais no Brasil devido ao uso do defensivo Malathion Emulsão Aquosa - EA 44\% no controle de Aedes Aegypti (Linnaeus, 1762) (díptera; culicidae): uma revisão

SILVA, C. P.; SAKAMOTO, G. K. D.; PONTES, M. P.; VIEIRA, R. R.; NATAL, J. P. S.; CONTE, H.

coloração avermelhada. O resultado é visível a olho nu sem a necessidade de empregar técnicas sofisticadas e tornando-se prático o seu uso “in loco" (BALA et al., 2017).

\section{DISCUSSÃO TEÓRICA}

\section{Biorremediação e alternativas biotecnológicas ao Malathion}

\section{Biorremediação}

A biorremediação surge como uma alternativa que visa transformar pesticidas em compostos mais simples e pouco contaminantes com o emprego do potencial metabólico de micro-organismos. Seu sucesso depende de vários fatores, das quais menciona-se a capacidade competitiva dos micro-organismos, biodisponibilidade, a concentração do organofosforado, umidade, $\mathrm{pH}$, temperatura e tipo de solo, presença de nutrientes e concentração do inóculo (HERNANDEZ-RUIZ et al., 2017). Várias bactérias, alguns fungos e cianobactérias têm sido relatados como biorremediadores de pesticidas organofosforados, utilizando seus compostos como fonte de carbono, nitrogênio ou fósforo (UKAB et al., 2016).

Enzimas estão presentes e desempenham papel-chave na degradação de qualquer componente xenobiótico, incluindo pesticidas no organismo alvo, por mecanismos de detoxificação intrínseca e resistência metabólica, assim como ambientalmente, pela biodegradação por micro-organismos presentes no solo e na água (UKAB et al., 2016).

Dados de literatura indicam que os micro-organismos mais utilizados na biorremediação de pesticidas organofosforados são pertencentes aos gêneros Serratia, Bacillus e Pseudomonas. No caso do Malathion, cita-se Pseudomonas putida, Brevibacillus sp. e Bacillus cereus (HERNANDEZ-RUIZ et al., 2017). Em outro estudo cita-se outras duas espécies além do $B$. cereus: $B$. subtilis e $B$. safensis, com potencial biorremediador em ordem decrescente (ISHAG et al., 2016).

A cepa do fungo Fusarium oxysporum JASA1 demonstrou ser eficaz na biorremediação do pesticida tanto no solo livre após 9 dias quanto no solo enriquecido com carbono, nitrogênio e fósforo após 8 dias, podendo ser utilizado na remediação de solos (PETER et al., 2015).

As cianobactérias são capazes de degradar e utilizar o pesticida Malathion como fonte de nitrogênio em ambiente aquático. Cepas de três cianobactérias foram estudadas (Anabaena oryzae, Nostoc muscorum e Spirulina platensis), sendo que a espécie N. muscorum demonstrou ser a mais eficiente, com uma taxa de remoção do pesticida maior que 90\% (IBRAHIM et al., 2014).

\section{Mosquitos transgênicos}

Outra alternativa biotecnológica é o emprego de mosquitos transgênicos no combate ao mosquito da dengue e consequentemente evitar a utilização do Malathion. Segundo Ruffato et al. (2015) a linhagem do mosquito da dengue Aedes aegypti OX513A², parece ser promissora para a redução da frequência do

\footnotetext{
2 Organismo Geneticamente Modificado - OX513A é produzido pela empresa Oxitec, que tem a sede na cidade de Campinas, estado em São Paulo. Disponível em: https://www.oxitec.com/friendly-mosquitoes/brazil/
} 
Os riscos ambientais no Brasil devido ao uso do defensivo Malathion Emulsão Aquosa - EA 44\% no controle de Aedes Aegypti (Linnaeus, 1762) (díptera; culicidae): uma revisão

mosquito selvagem e apresenta algumas vantagens, porém são necessários mais testes sobre os riscos potenciais dessa tecnologia.

No entanto, os autores Capurro et al. (2016), relatam caso de sucesso no programa PAT (Aedes Transgenic Project ou Projeto Aedes Transgênico, na qual foi estabelecida uma parceria conjunta entre a Moscamed $^{3}$ e a Universidade de São Paulo (USP), apoiado pelo Ministério da Saúde (MS), a Secretária da Saúde do Estado da Bahia (SESAB), e pela Prefeitura Municipal de Juazeiro).

O objetivo do programa segundo Capurro et al. (2016), era de avaliar aqui no Brasil, a viabilidade do uso de uma linhagem transgênica (OX513A - a mesma usada nas ilhas de Cayman) visando suprimir a população $A$. aegypti. Os resultados de liberação de macho OX513A atingiu o objetivo, e reduziu em 95\% com base em dados de armadilhas para adultos e $78 \%$ com base em índices de ovitrampa ${ }^{4}$ comparados à área de controle adjacente sem liberação (CARVALHO et al., 2015).

\section{Mosquitos esterilizados por irradiação}

O controle do A. aegypti é por irradiação é uma alternativa, que consiste em tratar os insetos machos com uma dose mínima de raios gama ou raios $\mathrm{X}$ para induzir rearranjos cromossômicos aleatórios e provocar esterilização dos machos (ZARA et al., 2016). Estes machos libertos irão cruzar com as fêmeas selvagens, minimizando o potencial reprodutivo da população selvagem e hospedeira do vírus, reduzindo assim a população dos portadores virais nas gerações subsequentes (FACÓ et al., 2017).

\section{CONCLUSÕES}

O defensivo Malathion através de estudos realizados in vivo em animais como: $C$. carpio (carpas), $R$. norvegicus (ratos Wistar) e em testes in vitro com células de linhagens humanas, demonstra ter efeitos tóxicos em baixas concentrações. Entretanto apenas relatos de casos ainda são catalogados, quando o assunto se refere a humanos e, portanto, há necessidade de mais estudos sobre o Malathion para melhor entendimento de seus efeitos sobre os seres vivos e o meio ambiente.

\section{REFERÊNCIAS}

ABRASCO. Associação Brasileira de Saúde Coletiva. Nota técnica sobre microcefalia e doenças vetoriais relacionadas ao Aedes aegypti: os perigos das abordagens com larvicidas e nebulizações químicas - fumacê. ABRASCO, 2016

AGROFIT. Sistema de Agrotóxicos Fitossanitários. Consulta de produtos formulados. AGROFIT, 2018.

BALA, R.; DHINGRA, S.; KUMA M.; BANSAL, K.; MITTAL, S.; SHARMA R. K.; WANGOO, N.. Detection of organophosphorus pesticide: Malathion in environmental samples using peptide and aptamer based nanoprobes.
Chemical Engineering Journal, v.311, p.111-116, 2017.

BRASIL. Ministério da Saúde. Aedes Aegypti: Ministério da Saúde alerta para risco de surto de dengue, zika e chikungunya em municípios brasileiros. MS, 2018.

BRASIL. Ministério da Saúde. Recomendações sobre o uso de Malathion Emulsão Aquosa - EA 44\% para o controle de Aedes aegypti em aplicações espaciais a Ultra Baixo Volume (UBV). MS, 2014.

CAPURRO, M. L.; CARVALHO, D. O.; GARZIERA, L.; PEDROSA,

\footnotetext{
${ }^{3}$ MOSCAMED ou BIOFBRICA MOSCAMED BRASIL, consiste ser uma associação civil de direito privado, sem fins lucrativos, que tem sua sede e foro no Município de Juazeiro, Estado da Bahia. Disponível em: <http://www.moscamed.org.br>.

${ }^{4}$ Ovitrampa consiste em ser um método mais sensível e específico para monitorar a população de Aedes aegypti, além de ser o mais barato e o único que não é protegido por patente. Disponível em: <http://www.fiocruz.br/ioc/cgi/cgilua.exe/sys/start.htm?infoid=2135\&sid=32\&tpl=printerview>.
} 
M. C.; DAMASCENO, I.; LIMA, I.; DUARTE, B.; VIRGÍNIO, J. F.; LEES, R. S.; MALAVASI, A.. Description of Social Aspects Surrounding Releases of Transgenic Mosquitoes In Brazil. International Journal of Recent Scientific Research, v.7, n.4, p.10363-10369, 2016.

CARVALHO, D. O.; MCKEMEY, A. R.; GARZIERA, L.; LACROIX, R.; DONNELLY, C. A.; ALPHEY, L.; MALAVASI, A.; CAPURRO, M. L.. Suppression of a field population of Aedes aegypti in Brazil by sustained release of transgenic male mosquitoes. PLOs Neglected Tropical Diseades, v.9, n.7, 2015.

COLEONE, C. C.. Avaliação da dissipação do inseticida malation utilizado em nebulização a ultrabaixo volume no controle da dengue: avaliação ecotoxicológica e de risco ambiental. Dissertação (Mestrado em Ciências) Universidade de São Paulo, São Paulo, 2014.

DAVID, M.; KARTHEEK, R. M.. Malathion acute toxicity in tadpoles of Duttaphrynus melanostictus, morphological and behavioural study. The Journal of Basic \& Applied Zoology, v.72, p.1-7, 2015.

ESPINOZA-NAVARRO, O.; BUSTOS-OBREGÓN, E.. Effects of Malathion on Cellularity and Sperm Differentiation in Testis and Epididymis of Adult Rats. International Journal of Morphology, v.32, n.1, p.119-124, 2014.

FACÓ, J. F. B.; ACÁCIO, A.. Aplicação de opções reais em uma tríplice epidemia: análise de 3 estudos. In: CONFERENCE SAFETY, HEALTH AND ENVIRONMENT WORLD CONGRESS, 17. Anais. Vila Real, 2017.

GULARTE, J. A.; ROSA, T. D.; MEDEIROS, D. C.; PRATES, J. F.; ALMEIDA, A. S.; PANOZZO, L. E.. Tratamento de sementes com Malathion e qualidade fisiológica de sementes de arroz. Revista Científica Rural, v.20, n.2, 2018.

GUYTON, K. Z.; RUSYN, I.; CHIU, W. A.; CORPET, D. E.; VAN DEN BERG, M.; ROSS, M. K.; CHRISTIANI, D. C.; BELAND, F. A.; SMITH, M. T.. Application of the key characteristics of carcinogens in cancer hazard identification. Carcinogenesis, v.39, n.4, p.614-622, 2018.

HERNANDEZ-RUIZ, G. M.; ALVAREZ-OROZCO, N. A.; RIOSOZORIO, L. A.. Biorremediación de organofosforados por hongos y bacterias en suelos agrícolas: revisión sistemática. Corpoica Ciencia y Tecnología Agropecuaria, v.18, n.1, p.138-159, 2017.

IARC. International Agency for Reasearch on Cancer. Evaluation of five organophosphate insecticides and herbicides. Paris: IARC, 2015.

IBRAHIM, W. M.; KARAM, M. A.; EL-SHAHAT, R. M.; ADWAY, A. A.. Biodegradation and Utilization of Organophosphorus Pesticide Malathion by Cyanobacteria. BioMed Research International, v.2014, n.392682, p.6, 2014.

ISHAG, A. E.; ABDELBAGI, A. O.; HAMMAD, A. M.; ELSHEIKH, E. A.; ELSAID, O. E.; HUR, J. H.; LAING, M. D.. Biodegradation of Chlorpyrifos, Malathion, and Dimethoate by Three Strains of Bacteria Isolated from Pesticide-Polluted Soils in Sudan. Journal of Agricultural and Food Chemistry, v.64, p.84918498, 2016.
JAMES, T.; WYKE, S.; MARCZYLO, T.; COLLINS, S.; GAULTON, T.; FOXALL, K.; AMLÔT, R.; DUARTE-DAVIDSON R.. Chemical warfare agent simulants for human volunteer trials of emergency decontamination: A systematic review. Journal of Applied Toxicology, v.38, n.1, p.113-121 2018.

JOSSE, R.; SHARANEK, A.; SAVARY, C. C.; GUILLOUZO, A. Impact of isomalathion on Malathion cytotoxicity and genotoxicity in human HepaRG cells. Chemico-Biological Interactions, v.209, p.68-76, 2014.

LEME, T. S.; PAPINI, S.; VIEIRA, E. ; LUCHINI, L. C.. Avaliação da vestimenta utilizada como equipamento de proteção individual pelos aplicadores de malationa no controle da dengue em São Paulo, Brasil. Cadernos de Saúde Pública, v.30, n.3, p.567-576, 2014.

MELLO, N. P.. Recuperação de peixes juvenis de Oreochromis niloticus após a intoxicação aguda com o inseticida Malathion. Dissertação (Mestrado em Aquicultura) - Universidade Estadual Paulista, Jaboticabal, 2018.

PESSOA, J. M.; OLIVEIRA, E. S. F.; TEIXEIRA, R. A. G.; LEMOS, C. L. S.; BARROS, N. F.. Controle da dengue: os consensos produzidos por Agentes de Combate às Endemias e Agentes Comunitários de Saúde sobre as ações integradas. Revista Ciência \& Saúde Coletiva, v.21, n.8. p.2329-2338, 2016.

PETER, L.; GAJENDIRAN, A.; MANI, D.; NAGARAJ, S.. Mineralization of Malathion by Fusarium oxysporum Strain JASA1 Isolated from Sugarcane Fields. Environmental Progress \& Sustainable Energy, v.34, n.1, p.112-116, 2015.

POSSAVATZ, J.; ZEILHOFER, P.; PINTO, A. A.; TIVES, A. L.; CARVALHO DORES, E. F. G.. Resíduos de pesticidas em sedimento de fundo de rio na Bacia Hidrográfica do Rio Cuiabá, Mato Grosso, Brasil. Revista Ambiente \& Água, v.9, n.1, p.83-96, 2014.

REED, N. R.; RUBIN, A. L.. Malathion. In: Encyclopedia of Toxicology. 2014. p.133-137.

RUFFATO, C. R.; CONTE, H.. Mosquito Transgênico Aedes aegypti no Brasil: LINHAGEM OX513A. Revista UNINGÁ Review, v.22, n.1, p.20-23, 2015.

SANTOS, J. R. J.; ROCHA, A. M.. Análise dos domínios biotecnológicos empregados em patentes para combate ao mosquito Aedes aegypti, sob enfoque patentário. Revista Ciências Médicas e Biológicas, v.17, n.1, p.20-26, 2018.

SEUNGUPTA, P.; BANERJEE, R.. Environmental toxins: Alarming impacts of pesticides on male fertility. Human and Experimental Toxicology, v.33, n.10, p.1017-1039, 2014.

SINHA, S.; YADAV, G.; KAUSHIK, B. R.; DOUNDE, S.; JANGHEL, D.. Histopatological impact of Malathion on the testicular cells of freshwater crabs barytelhusa cunicularis (westwood, 1836). World Journal of Pharmacy dnd Pharmaceutical Sciences, v.7, 997-1009, 2018.

UKAB, B.; MUDASIR, S.; NAZIR, R.. Review on Bioremediation of Pesticides. Journal of Bioremediation \& Biodegradation, v.7, n.3, p.0-5, 2016. 
Os riscos ambientais no Brasil devido ao uso do defensivo Malathion Emulsão Aquosa - EA 44\% no controle de Aedes Aegypti (Linnaeus, 1762) (díptera; culicidae): uma revisão

SILVA, C. P.; SAKAMOTO, G. K. D.; PONTES, M. P.; VIEIRA, R. R.; NATAL, J. P. S.; CONTE, H.

VALDEZ, A. L. D.; SIBONA, G. J.; CONDATA, C. A.. Impact of rainfall on Aedes aegypti populations. Ecological Modelling, v.308, pg. 96-105, 2018.

YONAR, S. M.; URAL, M. Ş.; SILICI, S.; YONAR, M. E.. Malathion-induced changes in the haematological profile, the immune response, and the oxidative/antioxidant status of Cyprinus carpio carpio: Protective role of propolis.
Ecotoxicology and Environmental Safety, v.102, p.202-209, 2014.

ZARA, A. L. S. A.; SANTOS, S. M.; FERNANDES-OLIVEIRA, E. S.; CARVALHO, R. G.; COELHO, G. E.. Estratégias de controle do Aedes aegypti: uma revisão. Revista Epidemiologia Serviço de Saúde, v.25, n.2, p.391-404, 2016.

A CBPC - Companhia Brasileira de Produção Científica (CNPJ: 11.221.422/0001-03) detém os direitos materiais desta publicação. Os direitos referem-se à publicação do trabalho em qualquer parte do mundo, incluindo os direitos às renovações, expansões e disseminações da contribuição, bem como outros direitos subsidiários. Todos os trabalhos publicados eletronicamente poderão posteriormente ser publicados em coletâneas impressas sob coordenação da Sustenere Publishing, da Companhia Brasileira de Produção Científica e seus parceiros autorizados. Os (as) autores (as) posteriormente ser publicados em coletâneas impressas sob coordenação da Sustenere Publishing, da Companhia Brasileira de Produção Cientifica e seus parce
preservam os direitos autorais, mas não têm permissão para a publicação da contribuição em outro meio, impresso ou digital, em português ou em tradução. 